\title{
Study of Factors Associated with Sarcopenia in COPD Patients
}

\author{
Saleh Ahmed *1
}

\begin{abstract}
Introduction: Sarcopenia is frequently associated with chronic diseases such as chronic obstructive pulmonary disease (COPD). Sarcopenia can be classified as physical frailty where frailty is associated with adverse health outcomes. Sarcopenia was found to be associated with worsening lung function in male COPD patient. Objective was to find out the factors associated with sarcopenia in COPD patients. Materials \& Methods: This was cross-sectional observational study was carried out Different Privet Medical in Chandpur and Chandpur Medical College Hospital, Chandpur. Patients diagnosed with COPD according to Global Initiative for Chronic Obstructive Pulmonary Disease (GOLD) guidelines were included in this study. Exclusion criteria were unstable cardiac disease, an exacerbation within the preceding 4 weeks, predominant neurological limitation to walking (eg, significant hemiplegia) or contraindication to bioelectrical impedance analysis (BIA) including an implanted pacemaker or defibrillator. All participants gave written informed consent. EWGSOP criteria were applied to outpatients with stable COPD. Results: In uniavariate analysis, age, moderate COPD, severe COPD, obesity, non-elective admission over the past 12 months, $M M R C$ scale and MAP were significantly associated with sarcopenia. In multivariate analysis, age, moderate COPD, severe COPD, obesity and MMRC scale were significantly associated with sarcopenia. Conclusion: Prevalence of sarcopenia was $26 \%$. Independent factors associated with sarcopenia Age (>70 years) years (adjusted odds ratio $(A O R)$ 4.387. Sarcopenia affects about one-quarter of COPD patients. Age, severity of COPD, MMRC scale, and BMI status were the factors associated with sarcopenia.
\end{abstract}

Keywords: Airway obstruction, Body composition, Sarcopenia, COPD.

Number of Tables: 03; Number of References: 22; Number of Correspondence: 06.

*1. Corresponding Author:

Dr. Saleh Ahmed, MBBS, FCPS

Senior Consultant

Department of Medicine

250 beded General Hospital, Chandpur.

E- mail: pdrc4006@gmail.ocm

Mobile: 01731190278

\section{Introduction:}

Sarcopenia is frequently associated with chronic diseases such as chronic obstructive pulmonary disease (COPD) and cancer. COPD, which is characterized by an irreversible airflow limitation, exacerbates respiratory distress as the disease progresses. The prevalence of sarcopenia in stable COPD was reported to be $15 \%$ to $25 \%$ in previous foreign studies $^{1}$. Chronic obstructive pulmonary disease (COPD) has been described as a systemic disease. Sarcopenia is one of the systemic effects that are related to several adverse outcomes.

Sarcopenia can be classified as physical frailty where frailty is associated with adverse health outcomes ${ }^{2,3}$. Sarcopenia was found to be associated with worsening lung function in male COPD patients ${ }^{4}$. COPD patients also have relative or an absolute increase in fat mass which might contribute to systemic inflammation, loss of fat-free mass, and insulin resistance. Fat-free mass index, not body mass index (BMI), was significantly related to pulmonary function, dyspnea severity, quality of life, and reflected reduced skeletal muscle mass ${ }^{5,6}$.

In patients with COPD, such changes have been shown to be related to exercise intolerance, impaired quality of life, and increased mortality ${ }^{7}$. Few studies in the literature have correlated the prevalence of sarcopenia with indices of COPD severity. In addition, to date, there have been no studies correlating sarcopenia with the prognosis of COPD or correcting sarcopenia by the BMI to avoid misdiagnosis in overweight patients.

\section{Materials and Methods:}

This was cross-sectional observational study was carried out Different Privet Medical in Chandpur and Chandpur Medical College Hospital, Chandpur during January 2019 to December 2019. Among 100 patients diagnosed with COPD according to Global Initiative for Chronic Obstructive Pulmonary Disease (GOLD) guidelines were included in this study. Exclusion criteria were unstable cardiac disease, an exacerbation within the preceding 4 weeks, predominant neurological limitation to walking (eg, significant hemiplegia) or contraindication to bioelectrical impedance analysis (BIA) including an implanted pacemaker or defibrillator. All participants gave written informed consent. EWGSOP criteria were applied to outpatients with stable COPD. Body composition, exercise capacity, 
functional performance, physical activity and health status were assessed. Using a case-control design, response to PR was determined in patients with sarcopenia and a propensity score-matched non-sarcopenic group for Uniavariate and multivariate analysis. Data collected was analysed using SPSS software version 23 and $\mathrm{p}$ value was considered $<0.05$ as significant.

\section{Results:}

Thirty eight (38.0\%) patients were belonged to age 61-70 years, 94(94.0\%) were male, 42(42.0\%) were complete primary education level, 91(91.0\%) were smoker, $53(53.0 \%)$ were moderate COPD, 39(39.0\%) were hypertension, 94(94.0\%) patients used inhaled corticosteroid, $64(64.0 \%)$ had normal BMI, mean MMRC scale was found $0.73 \pm 0.64$, mean barthel scores was $18.0 \pm 2.1$, mean MAP was $96.2 \pm 10.8 \mathrm{mmHg}, 38(38.0 \%)$ was found osteoporosis and $26(26.0 \%)$ was sarcopenia (Table-I).

Table I: Baseline characteristics of the study population.

\begin{tabular}{|c|c|c|}
\hline Num & of patients & Percentage \\
\hline \multicolumn{3}{|l|}{$\overline{\text { Age (years) }}$} \\
\hline$\leq 60$ & 27 & 27.0 \\
\hline $61-70$ & 38 & 38.0 \\
\hline$>70$ & 35 & 35.0 \\
\hline \multicolumn{3}{|l|}{ Sex } \\
\hline Male & 94 & 94.0 \\
\hline Female & 6 & 6.0 \\
\hline \multicolumn{3}{|l|}{ Educational level } \\
\hline Illiterate & 16 & 16.0 \\
\hline Primary & 42 & 42.0 \\
\hline $\mathrm{SSC}$ & 24 & 24.0 \\
\hline $\mathrm{HSC}$ & 13 & 13.0 \\
\hline Graduate & 5 & 5.0 \\
\hline \multicolumn{3}{|l|}{ Smoking status } \\
\hline Smoker & 91 & 91.0 \\
\hline Non smoker & 9 & 9.0 \\
\hline \multicolumn{3}{|l|}{ Severity of COPD } \\
\hline Mild & 26 & 26.0 \\
\hline Moderate & 53 & 53.0 \\
\hline Severe & 21 & 21.0 \\
\hline \multicolumn{3}{|l|}{ Comorbid diseases } \\
\hline Diabetes mellitus & 10 & 10.0 \\
\hline Hypertension & 39 & 39.0 \\
\hline Dyslipidemia & 10 & 10.0 \\
\hline Chronic arthritis & 9 & 9.0 \\
\hline Cancer & 3 & 3.0 \\
\hline \multicolumn{3}{|l|}{ Medication uses } \\
\hline Inhaled corticosteroid & 94 & 94.0 \\
\hline Systemic steroid & 1 & 1.0 \\
\hline Oral hypoglycemic drugs & 6 & 6.0 \\
\hline Statin & 10 & 10.0 \\
\hline NSAIDs & 1 & 1.0 \\
\hline \multicolumn{3}{|l|}{$\mathrm{BMI}\left(\mathrm{kg} / \mathrm{m}^{2}\right)$} \\
\hline Underweight $(<18.5)$ & 11 & 11.0 \\
\hline Normal (18.5-24.9) & 64 & 64.0 \\
\hline Over weight (25.0-29.9) & 18 & 18.0 \\
\hline Obesity $(\geq 30.0)$ & 7 & 7.0 \\
\hline
\end{tabular}

\begin{tabular}{lll}
\hline & Number of patients & Percentage \\
\hline $\begin{array}{l}\text { History of fall at least two } \\
\text { times over the past 12 months }\end{array}$ & 1 & 1.0 \\
$\begin{array}{l}\text { Nonelective admission over } \\
\text { the past 12 months }\end{array}$ & 25 & 25.0 \\
\hline Mean MMRC scale & 0.73 & \pm 0.64 \\
Mean Barthel scores & 18.0 & \pm 2.1 \\
Mean Chula IADLs scores & 9.1 & \pm 0.3 \\
Mean MAP (mmHg) & 96.2 & \pm 10.8 \\
Mean Gait speed (m/s) & 1.4 & \pm 0.2 \\
\hline Mean Handgrip strength $(\mathrm{kg})$ & & \\
$\quad$ Male & 26.8 & \pm 6.0 \\
$\quad$ Female & 22.0 & \pm 3.8 \\
\hline Mean skeletal mass index $\left(\mathrm{kg} / \mathrm{m}^{2}\right)$ & & \\
$\quad$ Male & 7.0 & \pm 0.8 \\
$\quad$ Female & 6.5 & \pm 0.5 \\
\hline Osteoporosis & 38 & 38.0 \\
Sarcopenia & 26 & 26.0 \\
\hline
\end{tabular}

In uniavariate analysis, age, moderate COPD, severe COPD, obesity, non-elective admission over the past 12 months, MMRC scale and MAP were significantly associated with sarcopenia (Table-II).

Table II: Uniavariate analysis for sarcopenia.

\begin{tabular}{lcll}
\hline & OR & 95\% CI (lower-upper) & \multicolumn{1}{c}{ P value } \\
\hline Age ( $>70$ years) & 4.387 & $1.430-9.703$ & $0.027^{\mathrm{s}}$ \\
Male & 1.121 & $0.472-3.497$ & $0.741^{\mathrm{ns}}$ \\
Smoker & 0.157 & $0.022-1.143$ & $0.068^{\mathrm{ns}}$ \\
Moderate COPD & 8.479 & $1.245-46.726$ & $0.009^{\mathrm{s}}$ \\
Severe COPD & 0.158 & $0.027-0.930$ & $0.041^{\mathrm{s}}$ \\
Diabetes mellitus & 3.961 & $0.392-40.034$ & $0.243^{\mathrm{ns}}$ \\
Hypertension & 2.719 & $0.162-45.721$ & $0.487^{\mathrm{ns}}$ \\
Dyslipidemia & 0.791 & $0.042-14.823$ & $0.875^{\mathrm{ns}}$ \\
Chronic arthritis & 3.258 & $0.509-20.860$ & $0.212^{\mathrm{ns}}$ \\
Cancer & 2.027 & $0.159-11.697$ & $0.838^{\mathrm{ns}}$ \\
Inhaled corticosteroid & 1.084 & $0.430-2.730$ & $0.864^{\mathrm{ns}}$ \\
Systemic steroid & 0.808 & $0.169-3.996$ & $0.087^{\mathrm{ns}}$ \\
Oral hypoglycemic drugs & 0.257 & $0.044-1.506$ & $0.132^{\mathrm{ns}}$ \\
Statin & 1.160 & $0.482-2.795$ & $0.740^{\mathrm{ns}}$ \\
NSAIDs & 1.045 & $0.136-8.034$ & $0.967^{\mathrm{ns}}$ \\
Obesity $\left(\geq 30.0 \mathrm{~kg} / \mathrm{m}^{2}\right)$ & 0.265 & $0.127-0.793$ & $0.036^{\mathrm{s}}$ \\
History of fall at least & & & \\
two times over the & 1.226 & $0.143-9.566$ & $0.983^{\mathrm{ns}}$ \\
past 12 months & & & \\
Nonelective admission 1.942 & $1.027-2.930$ & $0.047^{\mathrm{s}}$ \\
over the past 12 months & & & $0.048^{\mathrm{s}}$ \\
MMRC scale $(>0.4)$ & 1.572 & $1.132-3.434$ & $0.018^{\mathrm{s}}$ \\
MAP $(>100$ mmHg) & 6.479 & $1.124-24.976$ & $0.274^{\mathrm{ns}}$ \\
Osteoporosis & 1.784 & $0.783-3.465$ & \\
\hline
\end{tabular}

In multivariate analysis, age, moderate COPD, severe COPD, obesity and MMRC scale were significantly associated with sarcopenia (Table-III). 
Table III: Multivariate analysis for sarcopenia.

\begin{tabular}{lccl}
\hline & OR & $\begin{array}{c}\text { 95\% CI } \\
\text { (lower-upper) }\end{array}$ & P value \\
\hline Age ( $>70$ years) & 2.408 & $1.624-8.471$ & $0.039^{\mathrm{s}}$ \\
Moderate COPD & 6.448 & $1.338-39.812$ & $0.011^{\mathrm{s}}$ \\
Severe COPD & 1.685 & $1.031-2.382$ & $0.048^{\mathrm{s}}$ \\
Obesity $\left(\geq 30.0 \mathrm{~kg} / \mathrm{m}^{2}\right)$ & 0.462 & $0.219-0.970$ & $0.043^{\mathrm{s}}$ \\
Nonelective admission over & & & \\
the past 12 months & 0.933 & $0.651-1.479$ & $0.124^{\text {ns }}$ \\
MMRC scale $(>0.4)$ & 1.885 & $1.031-2.738$ & $0.048^{\mathrm{s}}$ \\
MAP $(>100 \mathrm{mmHg})$ & 0.764 & $0.204-0.986$ & $0.581^{\text {ns }}$ \\
\hline
\end{tabular}

\section{Discussion:}

In this study observed that thirty eight $(38.0 \%)$ patients were belonged to age $61-70$ years, $94(94.0 \%)$ were male, $42(42.0 \%)$ were complete primary education level, 91(91.0\%) were smoker, 53(53.0\%) were moderate COPD, $39(39.0 \%)$ were hypertension, 94(94.0\%) patients used inhaled corticosteroid, 64(64.0\%) had normal BMI, mean MMRC scale was found $0.73 \pm 0.64$, mean barthel scores was $18.0 \pm 2.1$, mean MAP was $96.2 \pm 10.8 \mathrm{mmHg}$, $38(38.0 \%)$ was found osteoporosis and $26(26.0 \%)$ was sarcopenia. In study of Limpawattana et al. ${ }^{8}$ reported that the majority of them were men (112 cases, $92.6 \%)$ with an age older than 65 years old (maximum age was 92 and minimum age was 47 years old). Most of them were ex-smokers with a moderate degree in severity of COPD. Hypertension was the most common comorbid disease. Low skeletal muscle mass was the main component, followed by low handgrip strength. Low gait speed was found in the minority. The possible explanations are the differences in body composition of different ethnicities and Asian people appear to have a higher prevalence of sarcopenia than other regions 9 . The study in Brazil regarding the prevalence of sarcopenia in COPD using DXA was $40 \%$; however, this report diagnosed sarcopenia using only low skeletal muscle mass which was defined as pre-sarcopenia in the current study. These figures were comparable to the report herein (48 cases, about $40 \%)^{10}$. Overall, the prevalence of pre-sarcopenia in this study is consistent with the previous data that reported the prevalence of sarcopenia in COPD using only low skeletal muscle mass that varied from $20 \%$ to $40 \%{ }^{4,11}$. The prevalence of sarcopenic obesity in Asia in existing studies is about 15\%; however, this current study used only skeletal muscle mass to detect sarcopenia ${ }^{4,12}$.

In current study observed in uniavariate analysis, age, moderate COPD, severe COPD, obesity, non-elective admission over the past 12 months, MMRC scale and MAP were significantly associated with sarcopenia. Limpawattana et al. ${ }^{8}$ also reported univariate analysis were entered in the multiple regression models: age, severity of COPD, MMRC scale, nonelective admission over the past 12 months, BMI, MPA, and presence of osteoporosis. Advancing age and severity of COPD showed high magnitudes of associations. Commonly, a progressive loss of muscle mass occurs at the age of 40 and is greater after 70 years ${ }^{13}$. Higher MMRC scale represented poorer pulmonary function that is also found its association with sarcopenia in this study ${ }^{14,15}$. Being underweight increased the risk of sarcopenia compared to obesity, the results support the findings that lower BMI was related to lower lean mass in COPD patients ${ }^{10}$. Subsequently, cigarette smoking alone did not show a significant association with sarcopenia ${ }^{10,16}$. Sarcopenia has been studied as an independent factor for decreased bone mineral density (BMD) due to the systemic consequences of $\mathrm{COPD}^{17}$.

In multivariate analysis, age, moderate COPD, severe COPD, obesity and MMRC scale were significantly associated with sarcopenia. Limpawattana et $a .^{8}$ reported after multicollinearity was checked, advanced age ( $>75$ years), greater severity of COPD, MMRC scale, and nonobese patients were the factors associated with sarcopenia in this study. There were factors associated with sarcopenia using multivariate analyses: age, severity of COPD, MMRC scale, and BMI. Advancing age and severity of COPD showed high magnitudes of associations. Commonly, a progressive loss of muscle mass occurs at the age of 40 and is greater after 70 years ${ }^{18}$. The decline in gait speed and grip strength was faster than muscle mass especially after the age of 70 years ${ }^{18,19}$. The MMRC scale increased the risk of sarcopenia. This finding was similar to the prior report ${ }^{20,21}$. This scale had been widely studied regarding its correlation with pulmonary function tests. Additionally, it could predict morbidity and mortality in COPD patients ${ }^{22}$. Higher MMRC scale represented poorer pulmonary function that is also found its association with sarcopenia in this study ${ }^{22}$.

\section{Conclusion:}

Prevalence of sarcopenia was $26 \%$. Independent factors associated with sarcopenia Age ( $>70$ years) years (adjusted odds ratio (AOR) 4.387. Sarcopenia affects about one-quarter of COPD patients. Age, severity of COPD, MMRC scale, and BMI status were the factors associated with sarcopenia.

\section{Conflict of Interest: None.}

\section{Acknowledgement:}

The authors would like to acknowledge all patients and their guardian for cooperate with this research and also be great full to Biopharma Limited to support all the way from the completion of the study.

\section{References:}

1. Kim SH, Shin MJ, Shin YB, Kim KU. Sarcopenia Associated with Chronic Obstructive Pulmonary Disease. J Bone Metab. 2019;26(2):65-74.

https://doi.org/10.11005/jbm.2019.26.2.65

PMid:31223602 PMCid:PMC6561852

2. Cruz-Jentoft AJ, Michelb JP. Sarcopenia: a useful paradigm for physical frailty. Eur Geri Med. 2013; 4: 102-105.

https://doi.org/10.1016/j.eurger.2013.02.009 
3. Angulo J, El Assar M, Rodriguez-Manas L. Frailty and sarcopenia as the basis for the phenotypic manifestation of chronic diseases in older adults. Mol Aspects Med. 2016; 50: 1-32.

https://doi.org/10.1016/j.mam.2016.06.001

PMid:27370407

4. Koo HK, Park JH, Park HK, Jung H, Lee SS. Conflicting role of sarcopenia and obesity in male patients with chronic obstructive pulmonary disease: Korean national health and nutrition examination survey. PLoS One. 2014; 9(10): e110448.

https://doi.org/10.1371/journal.pone.0110448

PMid:25353344 PMCid:PMC4212941

5. Pothirat C, Chaiwong W, Phetsuk N. The relationship between body composition and clinical parameters in chronic obstructive pulmonary disease. J Med Assoc Thai. 2016; 99(4): 386-393.

6. Wagner PD. Possible mechanisms underlying the development of cachexia in COPD. Eur Respir J. 2008; 31(3): 492-501. https://doi.org/10.1183/09031936.00074807

PMid: 18310396

7. Polkey MI, Moxham J. Attacking the disease spiral in chronic obstructive pulmonary disease. Clin Med. 2006;6(2):190-6.

https://doi.org/10.7861/clinmedicine.6-2-190

PMid:16688981 PMCid:PMC4953207

8. Limpawattana P, Inthasuwan P, Putraveephong S, Boonsawat W, Theerakulpisut D, Sawanyawisuth K. Sarcopenia in chronic obstructive pulmonary disease: A study of prevalence and associated factors in the Southeast Asian population. Chronic Respiratory Disease. 2018; 15(3): 250-257. https://doi.org/10.1177/1479972317743759

PMid:29186972 PMCid:PMC6100162

9. Beaudart C, Rizzoli R, Bruyere O, Reginster JY, Biver E. Sarcopenia: burden and challenges for public health. Arch Public Health. 2014; 72(1): 45.

https://doi.org/10.1186/2049-3258-72-45

PMid:25810912 PMCid:PMC4373245

10. Costa TM, Costa FM, Moreira CA, Rabelo LM, Boguszewski CL, Borba VZ. Sarcopenia in COPD: relationship with COPD severity and prognosis. J Bras Pneumol. 2015; 41(5): 415-421.

https://doi.org/10.1590/S1806-37132015000000040

PMid:26578132 PMCid:PMC4635087

11. Cesari M, Pedone C, Chiurco D, Cortese L, Conte ME, Scarlata S, et al. Physical performance, sarcopenia and respiratory function in older patients with chronic obstructive pulmonary disease. Age Ageing. 2012; 41(2): 237-241. https://doi.org/10.1093/ageing/afr167

PMid:22156558

12. Kim TN, Park MS, Yang SJ, Kang HJ, Song W, Seo JA, et al. Prevalence and determinant factors of sarcopenia in patients with type 2 diabetes: the Korean Sarcopenic Obesity Study (KSOS). Diabetes Care. 2010; 33(7): 1497-1499. https://doi.org/10.2337/dc09-2310

PMid:20413515 PMCid:PMC2890348

13. Kim TN, Choi KM. Sarcopenia: definition, epidemiology, and pathophysiology. J Bone Metab. 2013; 20(1): 1-10. https://doi.org/10.11005/jbm.2013.20.1.1

PMid:24524049 PMCid:PMC3780834

14. Mahler DA, Wells CK. Evaluation of clinical methods for rating dyspnea. Chest. 1988; 93(3): 580-586.

https://doi.org/10.1378/chest.93.3.580

PMid:3342669

15. Stenton C. The MRC breathlessness scale. Occup Med (Lond). 2008; 58(3): 226-227.

https://doi.org/10.1093/occmed/kqm162

PMid:18441368

16. Cruz-Jentoft AJ, Baeyens JP, Bauer JM, Boirie Y, Cederholm T, Landi F, et al. Sarcopenia: European consensus on definition and diagnosis: report of the European working group on sarcopenia in older people. Age Ageing. 2010; 39(4): 412-423.

https://doi.org/10.1093/ageing/afq034

PMid:20392703 PMCid:PMC2886201

17. Lee DW, Choi EY. Sarcopenia as an independent risk factor for decreased BMD in COPD patients: Korean national health and nutrition examination surveys IV and V (2008-2011). PLoS One. 2016; 11(10): e0164303.

https://doi.org/10.1371/journal.pone.0164303

PMid:27749901 PMCid:PMC5066961

18. Kim TN, Choi KM. Sarcopenia: definition, epidemiology, and pathophysiology. J Bone Metab. 2013; 20(1): 1-10. https://doi.org/10.11005/jbm.2013.20.1.1

PMid:24524049 PMCid:PMC3780834

19. Auyeung TW, Lee SW, Leung J. Age-associated decline of muscle mass, grip strength and gait speed: a 4-year longitudinal study of 3018 community-dwelling older Chinese. Geriatr Gerontol Int. 2014; 14(Suppl 1): 76-84.

https://doi.org/10.1111/ggi.12213

PMid:24450564

20. Jones SE, Maddocks M, Kon SS. Sarcopenia in COPD: prevalence, clinical correlates and response to pulmonary rehabilitation. Thorax. 2015; 70(3): 213-218.

https://doi.org/10.1136/thoraxjnl-2014-206440

PMid:25561517

21.Byun MK, Cho EN, Chang J. Sarcopenia correlates with systemic inflammation in COPD. Int J Chron Obstruct Pulmon Dis. 2017; 12: 669-675.

https://doi.org/10.2147/COPD.S130790

PMid:28255238 PMCid:PMC5325093

22. Stenton C. The MRC breathlessness scale. Occup Med (Lond). 2008; 58(3): 226-227.

https://doi.org/10.1093/occmed/kqm162

PMid:18441368 